\title{
LAS PINTURAS RUPESTRES DEL SITIO PAREDÓN BELLO (CORDÓN CHAPELCO), SAN MARTÍN DE LOS ANDES, NEUQUÉN, ARGENTINA
}

\section{THE ROCK PAINTINGS OF PAREDÓN BELLO (CORDÓN CHAPELCO), SAN MARTÍN DE LOS ANDES, NEUQUÉN, ARGENTINA}

\author{
AlBERTO E. PÉREZ* \& \\ GONZALO P. SALABERRY* *
}

Se presenta una caracterización detallada de las pinturas rupestres del sitio Paredón Bello, originalmente descrito en el año 1956 por Juan Schobinger. Las pinturas permiten establecer afinidades estilísticas y técnicas con la cuenca media del río Neuquén. Relevamientos previos en la vega Maipú y lago Lácar, ambos correspondientes a la cuenca hidrográfica del río Valdivia, han aportado en algunos casos sitios tipo para la definición de una modalidad estilística singular del estilo de grecas, la cual asociamos con motivos presentes en la cerámica del Período Alfarero Tardío del centro-sur de Chile, o Tradición Bicroma Rojo sobre Blanco.

Palabras clave: pinturas rupestres, Paredón Bello, San Martín de los Andes, Patagonia argentina

This paper offers a detailed characterization of the rock art of the Paredon Bello site, originally described in 1956 by Juan Schobinger. While the characterization allows us to identify technical and stylistic affinities with otherplaces in the middle reaches of the Neuquen river, other previously characterized sites in the Vega Maipu zone and Lacar lake, both in the Valdivia river basin, have in some cases been used as "typical sites" in defining a singular stylistic modality called the "grecas" style. We associate this style with motifs present on pottery from the Late Ceramic period of south central Chile, or the Red on White Bicolor Tradition.

Key words: rock paintings, Paredón Bello, San Martín de los Andes, Argentine Patagonia

\section{INTRODUCCIÓN}

Este trabajo forma parte de los nuevos relevamientos para la caracterización de sitios arqueológicos del ejido urbano de San Martín de los Andes, tarea llevada adelante por la Subsecretaría de Planificación y Desarrollo Sustentable de la Municipalidad de San Martín de los Andes, junto con la Subsecretaría de Gestión Ambiental y el Laboratorio de Arqueología y Etnohistoria municipal. Se desarrolla desde el año 2007, en el marco del proyecto "Arqueología del bosque meridional neuquino y su relación con sitios del área Paso Limay, estepa rionegrina y sectores transicionales" dirigido por uno de los autores. Al mismo tiempo que se ampliaron los registros y la caracterización de sitios conocidos y de otros novedosos, se inició un plan estratégico y sistemático de monitoreo de pinturas rupestres, proponiendo acciones concretas para la protección de sitios arqueológicos potencialmente afectados por el desarrollo urbanístico (Pérez et al. 2007). Como primera experiencia hemos caracterizado y revalorizado al histórico sitio Alero Gingin (Vignati 1935, 1963) en el contexto actual de las investigaciones regionales (Pérez et al. 2007), para, a continuación, ampliar la información de otros yacimientos novedosos como Cueva Alihuén (Pérez et al. 2014) y otros referidos

* Alberto E. Pérez, Universidad Maimónides (CEBBAD-Fundación Azara), y Laboratorio de Arqueología y Etnohistoria, Secretaría de Planificación y Desarrollo Sustentable, Municipalidad de San Martín de los Andes, Cte. Díaz y Rivadavia (8370), Neuquén, Argentina, email: arqueo.meliquina@ gmail.com

* Gonzalo P. Salaberry, Subsecretaría de Gestión Ambiental, Secretaría de Planificación y Desarrollo Sustentable. Municipalidad de San Martín de los Andes, Elordi y Roca (8370), Neuquén, Argentina, email: gonzalo.salaberry@smandes.gov.ar 
hace más de sesenta años e incorporarlos al contexto de las investigaciones regionales actuales.

En una visita que duró unas pocas horas, durante enero de 1953, Juan Schobinger registró el sitio Paredón Bello y describió sintéticamente sus pinturas. El informe, que presenta figuras muy esquemáticas, se incluyó en su obra clásica de arte rupestre de la provincia del Neuquén (Schobinger 1956). Caracterizó el arte de este sitio como: 1) exclusivo en el modo de ejecución pintado; 2) con una paleta de colores monocroma, integrada por variedades cromáticas de color rojo; 3) con estilos geométrico-ornamentales y simbólicos predominantes, compuestos de motivos escalonados, ćŕrculos con punto, cruciformes, líneas onduladas y otros de mayor apariencia significativa, o de tipo naturalista, compuestos de figuras antropomorfas simples y en combinación con otros signos.

Si bien no hay ninguna publicación específica del sitio, existen referencias o menciones sobre pinturas rupestres de la vega Maipú en trabajos divulgativos, donde se muestra una imagen correspondiente al sitio bajo la denominación de "La Cuevita" (Rodríguez 1999). Respecto de esto, resaltamos la caracterización previa y confirmamos la nomenclatura original de Paredón Bello.

\section{OBJETIVOS Y METODOLOGÍA}

En este trabajo presentaremos un nuevo relevamiento del sitio Paredón Bello, en el ejido urbano de San Martín de los Andes, sector oriental y naciente de la cuenca hidrográfica del río Valdivia, en la provincia de Neuquén, Argentina. Nos interesa particularmente caracterizar los motivos del sitio para establecer similitudes y diferencias no solo con otros estilos, modalidades y tendencias estilísticas regionales del arte rupestre, sino con otros tipos de soportes como la alfarería. Consideramos al ámbito cordillerano occidental como espacialmente integrado con nuestra área de estudio a partir de una misma cuenca hidrográfica, cuyo registro arqueológico presenta cada vez mayor cantidad y diversidad de caracteres compartidos.

Para la descripción y la caracterización del sitio se tomaron coordenadas geográficas y altura respecto del nivel del mar con GPS Garmín 78. A continuación, se procedió al registro planimétrico del sitio, la caracterización geológica y la composición de los soportes. La unidad mínima de análisis es el motivo. De la asociación entre motivos en relación anecdótica y que ocupen un espacio relativamente reducido, se discriminaron conjuntos de motivos (Gradin 1978). La organización espacial y la posición sobre el soporte de los motivos corresponde a la sectorización. Para su relevamiento cualitativo y cuantitativo se confeccionó una base de datos con los siguientes ítems: distribución y organización de motivos en los soportes para distinguir "sectores", reconociendo motivos aislados de conjuntos, y su orientación; las medidas alto y ancho discriminan tres variables como altura máxima del motivo, ancho máximo del motivo y por último ancho o grosor de la línea o trazo de los mismos, y altura respecto del nivel del suelo del sitio de cada motivo, presentado en forma promediada por sectores, detallando alturas mínimas y máximas cuando difieren sustancialmente. Se describe a continuación el modo de ejecución (pintura, grabado, etc.) y técnica empleada (trazo regular, digital, aplicación de pincel, etc.).

Para la caracterización estilística, y con el solo fin de establecer parámetros homologables y discusiones con trabajos previos, utilizamos el modelo clásico de Menghin (1957); mientras que para el análisis morfológico de los motivos utilizamos la propuesta de Gradin (1988), incluyendo nuestros resultados en las tendencias estilísticas regionales (Gradin 1999) y algunas modalidades propuestas (Albornoz 1996, 2003; Albornoz \& Cúneo 2000). Se detalla el estado de conservación, nuevamente promediado en este trabajo por sectores. Para la caracterización de color utilizamos escala colorimétrica Munsell Soil Color Charts (1975). En las imágenes fotográficas se incluyó la escala de referencia IFRAO.

\section{EL SITIO PAREDÓN BELLO}

Paredón Bello es un reparo rocoso (paredón, alero y abrigo) de carácter ignimbrítico y, en menor medida, formado por tobas o aglomerados. Tiene representaciones rupestres sobre soportes planos y lisos. Sus coordenadas geográficas son $-40^{\circ} 08^{\prime \prime} \mathrm{S}$ y $-70^{\circ} 17^{\prime \prime W}$. El soporte rocoso del sitio presenta una superficie de $36 \mathrm{~m}$ de ancho, 26 de alto y entre 6 y 12 metros cubiertos o reparados bajo línea de goteo. Se encuentra emplazado a una altura de $782 \mathrm{msnm}$ y a $95 \mathrm{~m}$ del nivel actual de la vega. Su acceso es relativamente dificultoso desde el valle, debido a que la pendiente natural presenta una inclinación mayor a $60^{\circ}$ y sectores con importante cobertura vegetal (fig. 1).

Topográficamente, el ámbito en el cual se encuentra el sitio y la cubeta del lago Lácar es un típico valle en forma de "U" de tipo glaciario, remodelado por acción hídrica sobre el sector oriental de la cuenca hídrica principal. Esta es de tipo exorreica y desagua hacia el Pacífico por intermedio del río Hua Hum. Esta cuenca está asentada en sucesivos escalones labrados por un glaciar, desde los $640 \mathrm{msnm}$ hasta Loma Atravesada, 860 msnm, formación que marca el límite de avance 


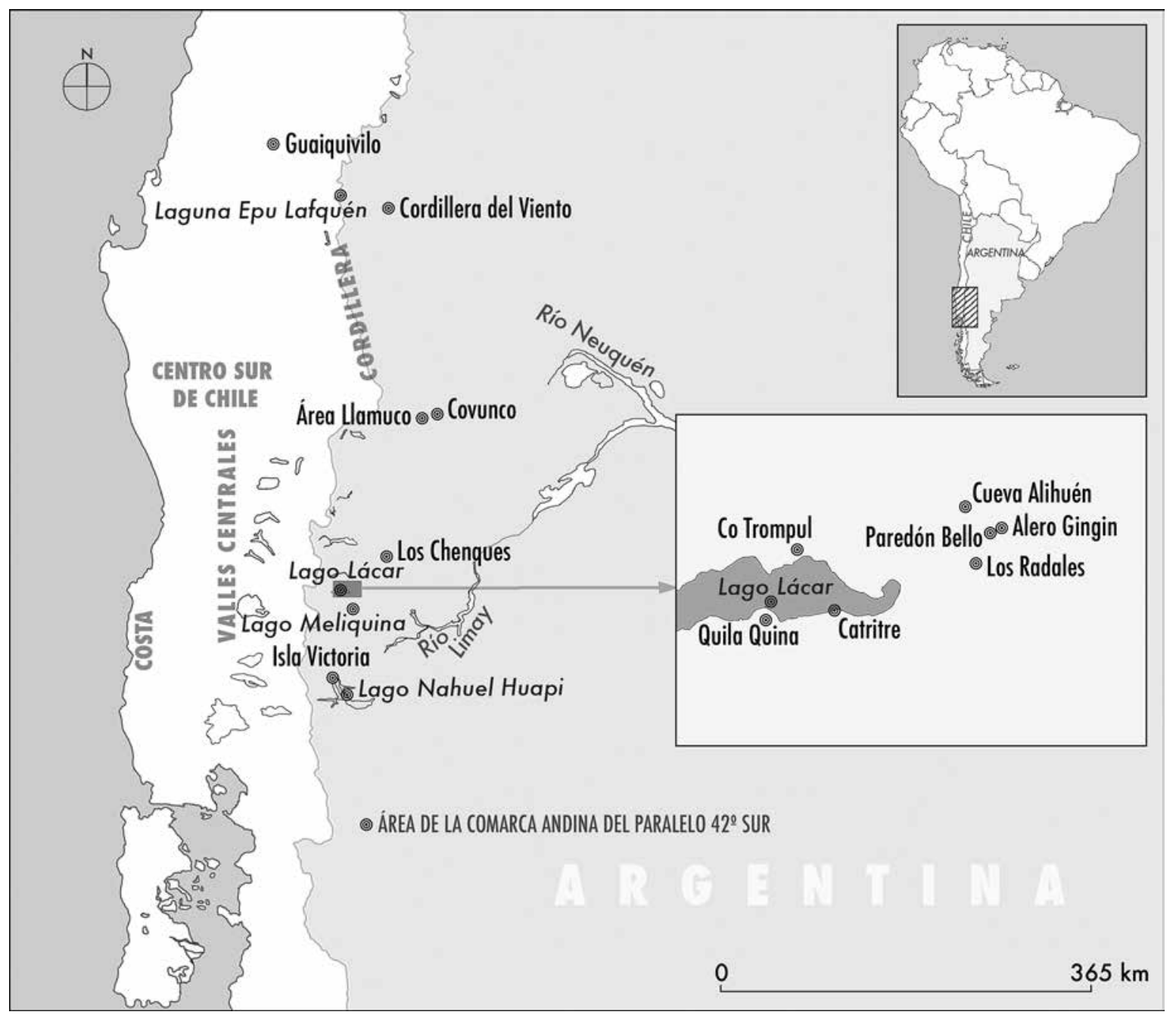

Figura 1. Plano general y ubicación de Paredón Bello.

Figure 1. General and specific location of Paredón Bello.

de los glaciares que modelaron la región, siendo este sector la divisoria de aguas de todo el sistema (Flint \& Fidalgo 1964; Fidalgo \& Porro 1978).

Según la clasificación de Köppen, el clima del área es templado húmedo. Las temperaturas en verano varían entre los $20^{\circ} \mathrm{C}$ y $30^{\circ} \mathrm{C}$ durante el día para descender por la noche a valores comprendidos entre los $0^{\circ} \mathrm{C}$ y 5 ${ }^{\circ} \mathrm{C}$ (Schroo et al. 2006, en Pérez et al. 2007). Las precipitaciones locales presentan un promedio de $1400 \mathrm{~mm}$. Los mayores volúmenes se registran en invierno, que acumula casi el $70 \%$ de las precipitaciones del año. El sitio se encuentra dentro de un sector relictual de bosque de ciprés de la cordillera (Austrocedrus chilensis). Como especies acompañantes se encuentran renovales de maitén, radal, maqui, laura y parrilla (Schroo et al. 2006, en Pérez et al. 2007), junto a introducidas como rosa mosqueta. Zoogeográficamente, la zona pertenece al Distrito Subandino Neuquino (Gollán 1958). Dentro del área se encuentran 166 especies de vertebrados nativos (Funes et al. 2006).

La zona de San Martín de los Andes se localiza en la provincia geológica de los Andes Patagónicos, en su segmento norte (Cordillera Patagónica Septentrional). Caracterizada como una faja plegada y corrida de retroarco, de edad terciaria, incluye pequeños sectores del arco volcánico actual, presentando litologías de diferentes edades y orígenes, las que fueron englobadas en la estructuración terciaria-cuaternaria.

En nuestra área de estudio afloran rocas volcánicas y volcanoclásticas pertenecientes a la Formación Ventana o su equivalente, denominada Auca Pan (Rabassa et al. 1987). Esta unidad estratigráfica presenta una gran variedad 
litológica. Si bien predominan las lavas de composiciones andesíticas y riodacíticas, las rocas piroclásticas son frecuentes y se presentan generalmente alternadas con las rocas volcánicas. En la zona de estudio y sectores aledaños las rocas aflorantes son predominantemente de tipo piroclásticas. En algunos casos, las características de las rocas aflorantes no permiten diferenciar con absoluta certeza si se trata de tobas andesíticas o de andesitas propiamente dichas.

Tres tipos de rocas piroclásticas han sido diferenciadas en el sector: ignimbritas (tobas de flujo), tobas y aglomerados volcánicos. Paredón Bello corresponde al primer tipo (fig. 2).

\section{DESCRIPCIÓN DE LA MUESTRA}

El emplazamiento del sitio presenta una excelente visión del valle húmedo y con pasturas tiernas que seguramente fue de gran atractivo para los ungulados (cérvidos y camélidos), el control de recursos animales para la caza y la circulación de personas por el valle desde múltiples direcciones, incluido el acceso a fuentes de materias primas como obsidianas. Se encuentra además muy cerca de otros sitios bajo reparo rocoso (incluso con pinturas rupestres) y campamentos a cielo abierto, potencialmente articulados de manera funcional. Durante la estación estival, el promontorio rocoso dentro del que está integrado el sector con pinturas permanece descubierto y visible en forma resaltante en el paisaje (figs. 3 y 4 ).

La muestra analizada está compuesta por un total identificable de 43 motivos con modo de ejecución pintado. Los abstractos son predominantes, con 41 elementos que constituyen el $95 \%$ de la muestra, mientras que los dos restantes son representativos (biomorfos), los que aportan menos del 5\% de la muestra total. El 93\% es pintura de tipo lineal, una combinada con cuerpo relleno, y solo uno de los motivos lineales presenta cuerpo relleno en su totalidad. Los dos representativos exhiben un motivo esquemático y otro estilizado. Sobre la muestra total, 22 motivos son rectilíneos, tres curvilíneos y 12 combinados.

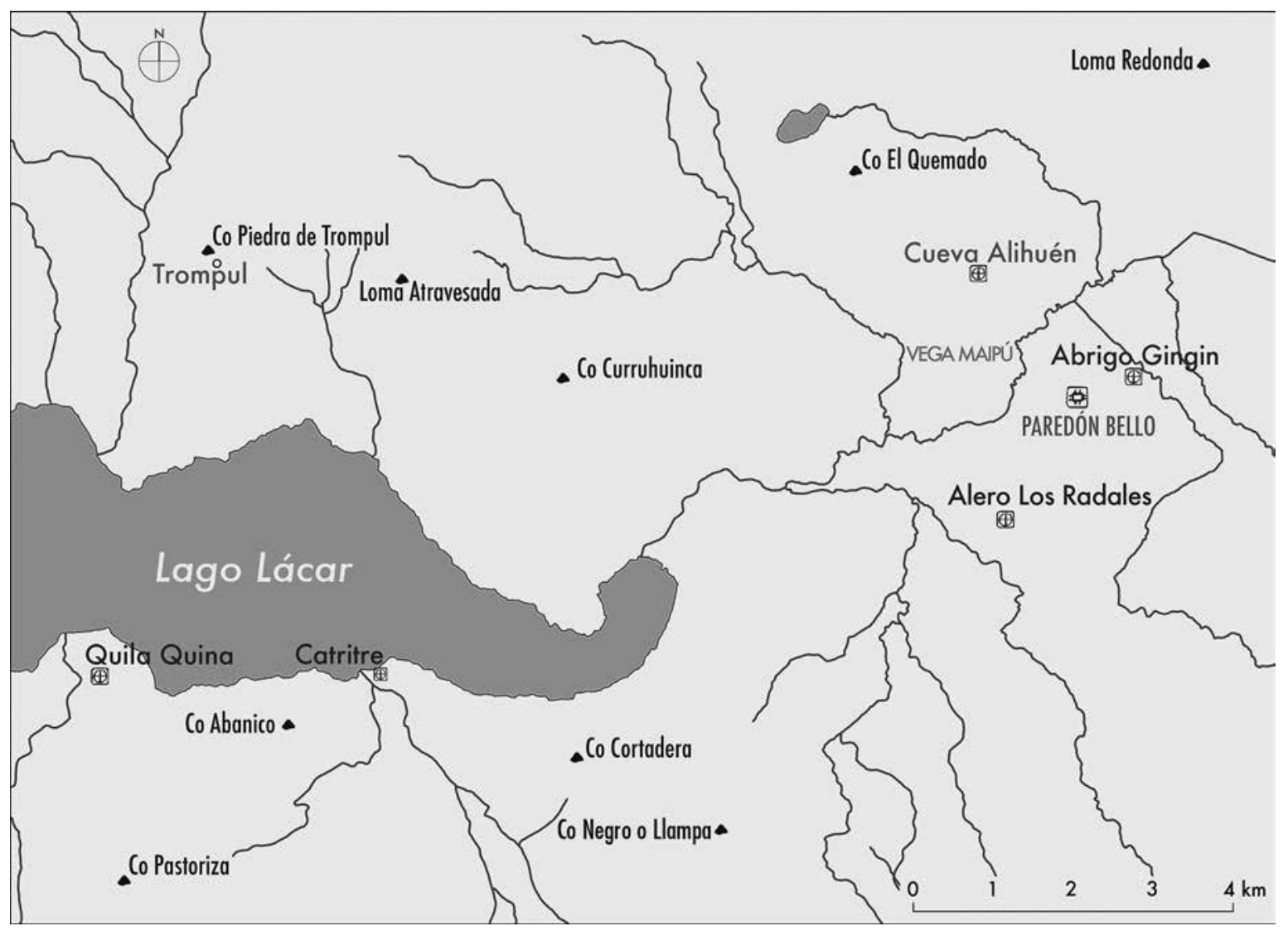

Figura 2. Ubicación de Paredón Bello y sitios cercanos de la vega Maipú y lago Lácar.

Figure 2. Location of Paredón Bello and sites near Vega Maipú and Lácar Lake. 


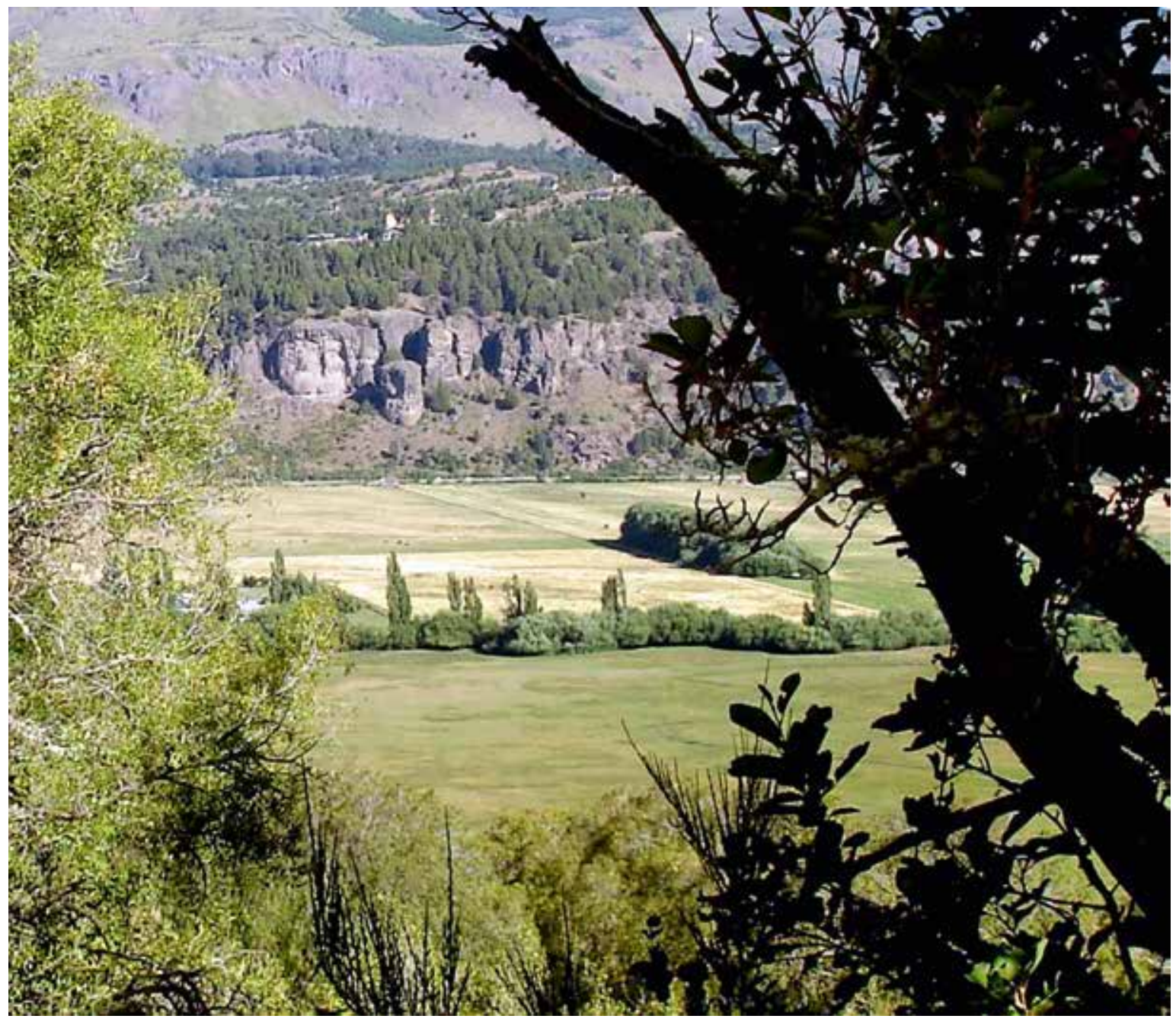

Figura 3. Vista de Paredón Bello desde la ladera norte de vega Maipú. Figure 3. View of Paredón Bello from the northern slope of Vega Maipu.

Los motivos se distribuyen a lo largo de dos soportes principales. A: el reparo rocoso propiamente dicho, B: un segundo nivel de suelo denudado parte de la misma formación rocosa. Schobinger (1956) lo consigna como una roca desprendida por referencias de un poblador local quien le aporta imágenes fotográficas para su descripción, ya que le había pasado inadvertida en su visita.

En el relevamiento de 1953, la cantidad de motivos presentes asciende a un total de 47 , solo limitado al soporte A, que a partir de nuestro trabajo hemos reducido a 43 motivos al integrar varios descritos previamente como diferentes en uno solo, separado por alteraciones de la superficie de la roca, tanto naturales como antrópicas (figs. 5 y 6 )
A diferencia de las descripciones previas, observamos que se han empleado al menos tres técnicas de ejecución de los motivos, dos de ellas exclusivamente pintadas, incluyendo entre estas a una de trazo igual o levemente mayor a $1 \mathrm{~cm}$ de ancho, quizá mediante una distribución de tipo digital. La otra técnica se compone de motivos geométricos que presentan un trazo delgado, igual e inferior a $\operatorname{los} 0,5 \mathrm{~cm}$ de ancho, donde posiblemente se hayan utilizado artefactos intermediarios para su ejecución, a modo de crayones, hisopos o pinceles. La tercera técnica incorpora el uso de características naturales de la geoforma para resaltar una protuberancia circular en relieve positivo, el cual es reproducido en par por medio de pintado para conformar una figura simétrica ocular, separada 


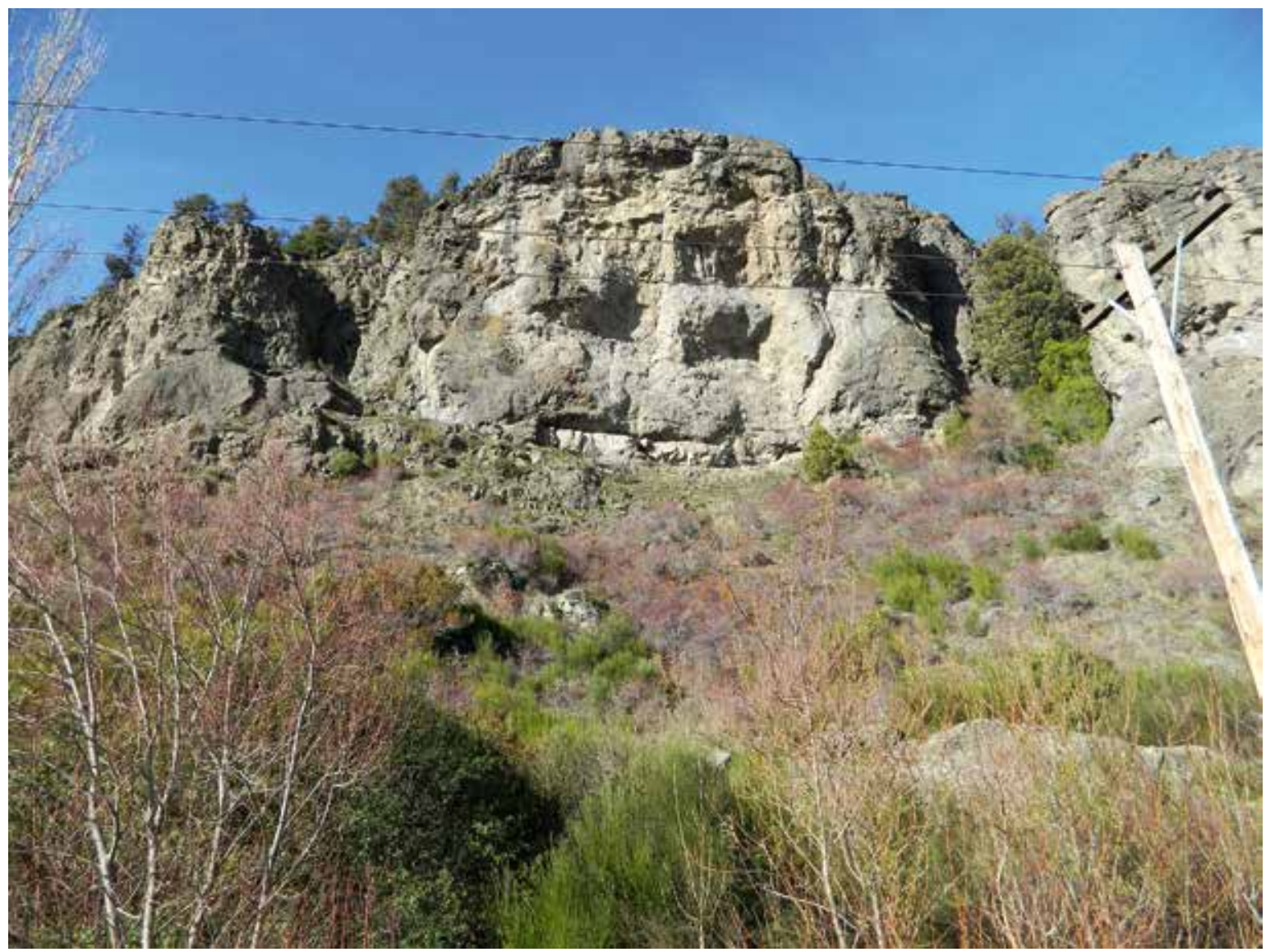

Figura 4. Detalle de promontorio rocoso y paredón con pinturas.

Figure 4. Detail of the rocky promontory and wall containing the paintings.

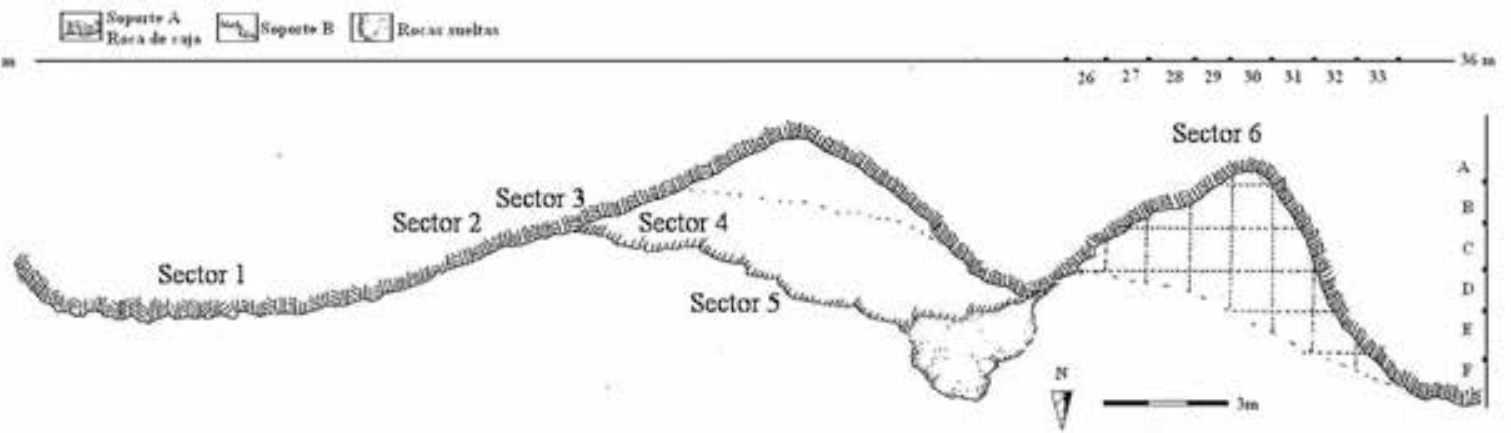

Figura 5. Planta de sitio Paredón Bello.

Figure 5. Plan of Paredón Bello site.

mediante pintura lineal conformando cejas y nariz, en caso de ser antropomorfa, o contorno de ojos y pico, en el caso de ser ornitomorfa (ver Fernández 2001).

La presencia de supuestos ornitomorfos nos remite a motivos del "estilo de La Araucanía", donde se describen líneas curvas sobre círculos, mayormente grabados, a los que denominan "búhos" (Mostny \& Niemeyer 1983; Castelleti 2007).

La superficie del reparo ha sido pintada en su total extensión. Organizamos su distribución en un mínimo de seis sectores de acuerdo con la disposición espacial, el soporte y las asociaciones de motivos (figs. 7 y 8). 


\section{Sector 1}

Se describen 26 motivos, entre los que reconocemos tres conjuntos de motivos. El promedio de medidas (alto y ancho) es de $16,4 \times 13,4 \times 0,62 \mathrm{~cm}$ y la altura respecto del suelo es de $1,30 \mathrm{~m}$.

Respecto de la paleta de colores, 25 motivos $(96,1 \%)$ son rojos y $1(3,9 \%)$ anaranjado. Sin embargo, a partir de la meteorización diferencial que delinea varios de los
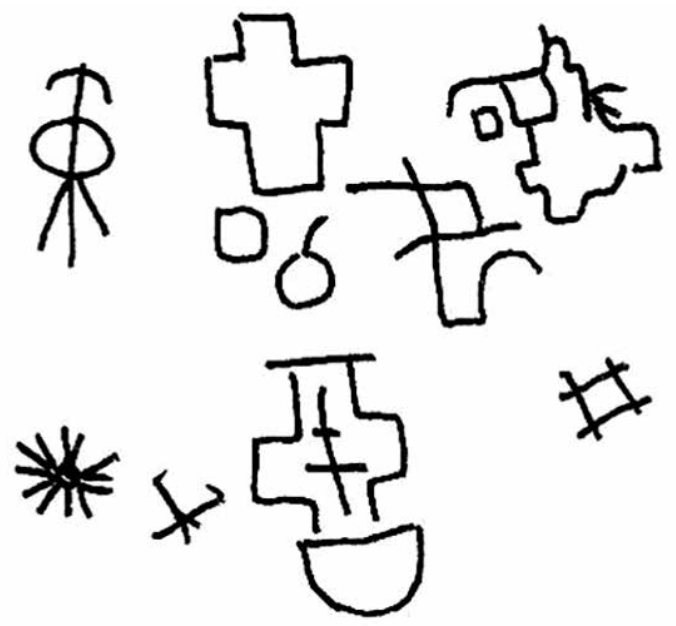

Figura 6. Motivos del Soporte B, hoy no visibles. Modificado de Schobinger (1956: 160, fig. 48). No presenta escala.

Figure 6. Motifs on Support B, no longer visible. Modified from Schobinger (1956: 160, fig. 48). No scale present. motivos geométricos rojos, se observa la antigua presencia de material cobertor (como pintura, por ejemplo) que, si bien ausente hoy día, ha perdurado el tiempo suficiente a la intemperie como para dejar su impronta negativa haciendo un contraste entre superficies más y menos meteorizadas. En suma, a diferencia de las consideraciones previas del sitio que refieran al carácter monocromo de las pinturas (Schobinger 1956), observamos que varios motivos eran originariamente bicromos, sobreviviendo solo hasta la actualidad la pintura color rojo y, en menor medida, anaranjado (figs. 9 y 10)

Los 26 motivos están realizados en la modalidad pintada de tipo lineal, incluyendo uno con cuerpo relleno $\mathrm{y}$ uno en relieve natural. La pintura parece haber sido dispuesta por al menos dos técnicas, la más recurrente es el arrastre digital, mientras dos motivos parecen haber sido ejecutados con crayones o instrumentos intermediarios como pincel o pluma. El 95,15\% de los motivos son abstractos y el $11,15 \%$, representativos. Sobre la conservación o su estado, 16 (61,5\%) son buenos y 10 $(38,5 \%)$ regulares, entre estos últimos, varios cubiertos por grafiti, mientras en otros casos se observan incompletos, asociados con evidencias de saqueo, como piqueteado, contorneado y negativos de extracción de soportes.

Los motivos son en su mayoría geométricos, adscribibles al estilo de grecas, incluyendo 24 abstractos, lineales compuestos de 15 representaciones rectilíneas (líneas rectas, escaleriformes, rombos, triángulos unidos
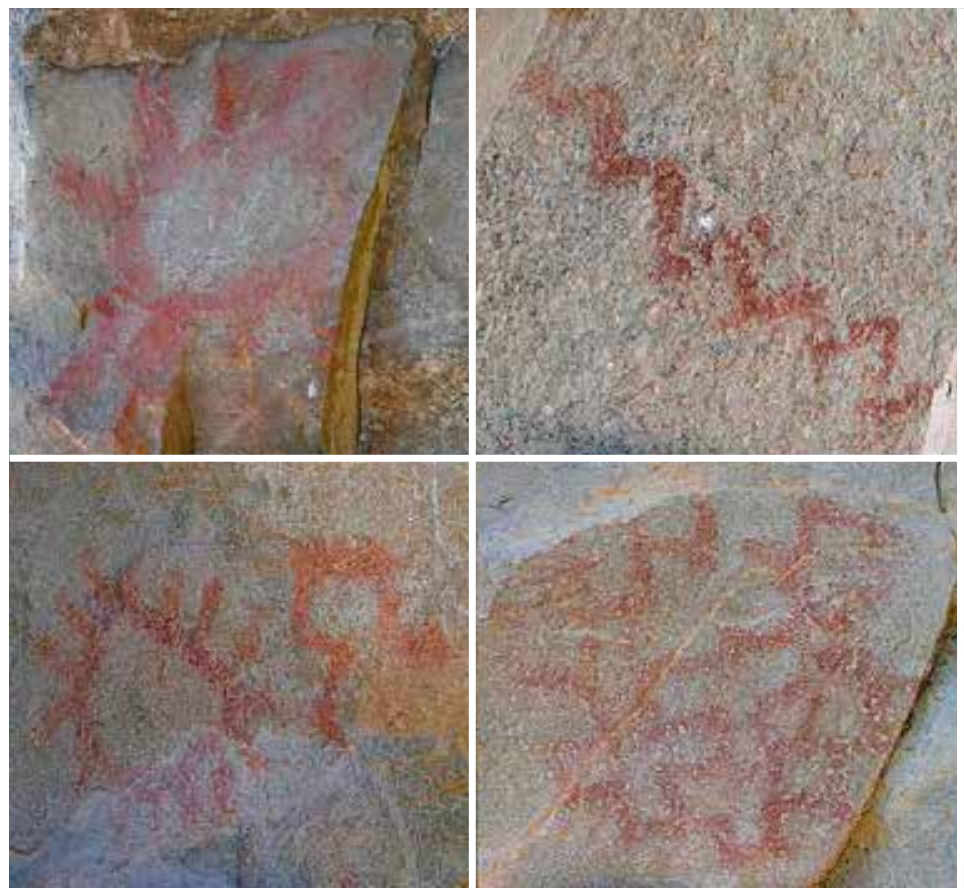

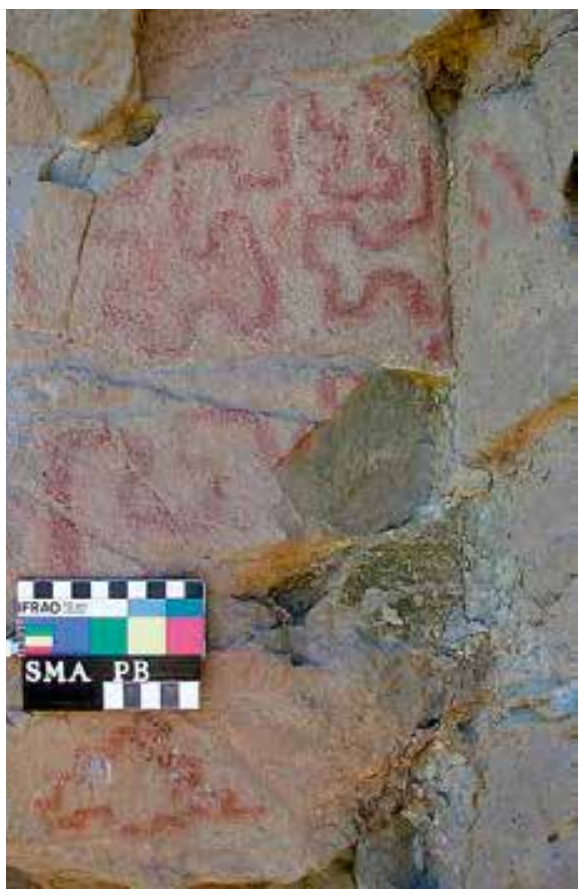

Figura 7. Motivos de Soporte A, Sector 1. Figure 7. Motifs on Support A, Sector 1. 


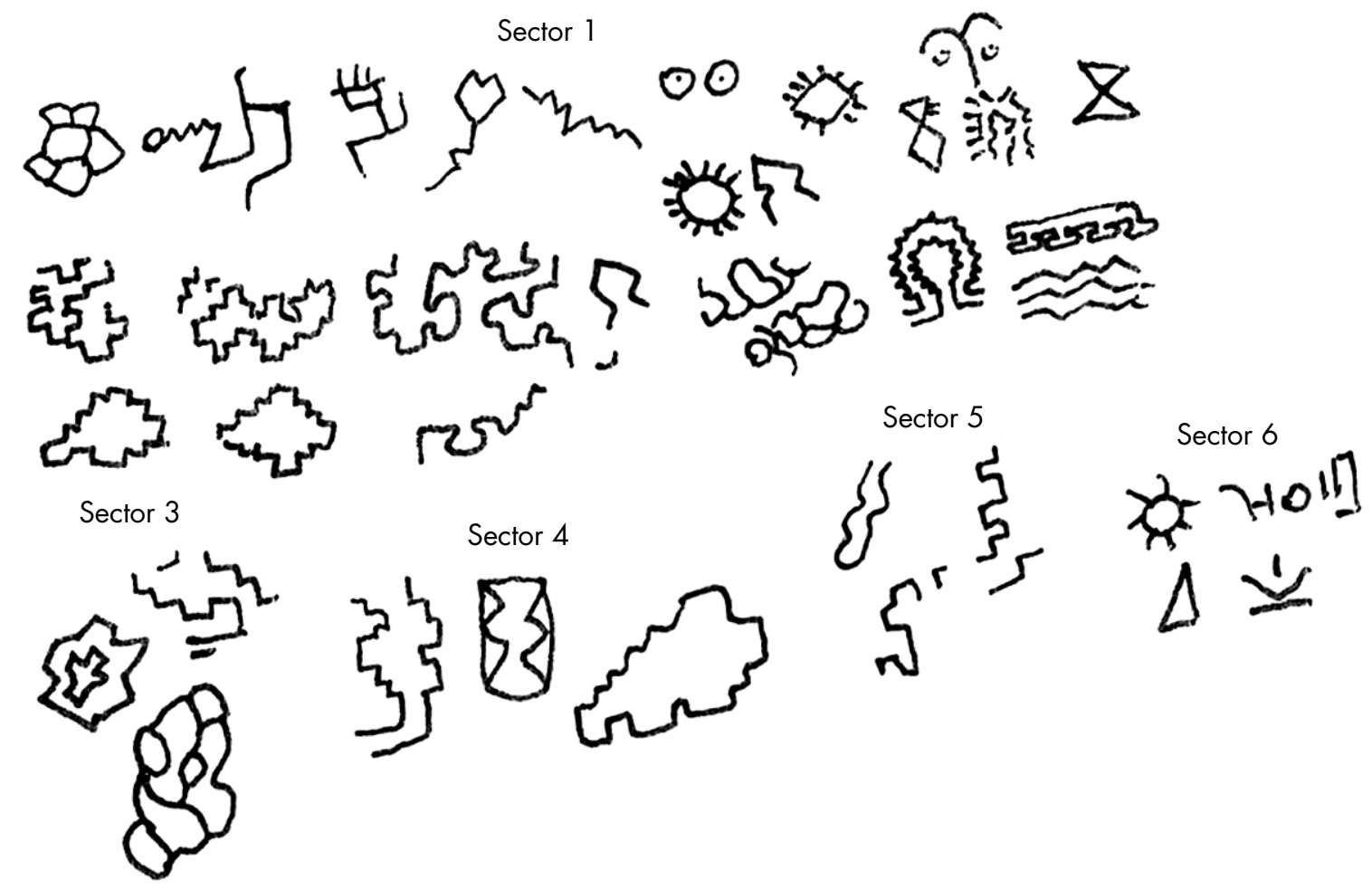

Figura 8. Motivos esquemáticos de Soporte A, sin escala y sin relación topográfica. Figure 8. Schematic motifs on Support A, without scale or topographic position.

por el vértice), dos curvilíneas (círculos) y ocho combinados (círculos con líneas radiantes, círculos con escaleriformes, líneas almenadas o en zigzag), uno de los motivos combina pintura lineal y cuerpo relleno, también segmentos curvilíneos y rectilíneos. Hay dos motivos representativos, uno corresponde a una figura estilizada de tipo biomorfa (zoomorfo en disposición dinámica), y otro corresponde a los motivos esquematizados de tipo biomorfos denominadas "oculados" (antropomorfo u ornitomorfo).

\section{Sector 2}

Este sector presenta un total de cuatro motivos, componiendo un $9,3 \%$ de la muestra total del sitio. Los motivos se distribuyen de forma aislada, o sea, que no se reconocen claramente conjuntos o asociaciones. Las medidas promediadas son $10,5 \times 14,5 \times 0,45 \mathrm{~cm}$ y la altura respecto del suelo promedio es de $1,25 \mathrm{~m}$.

La paleta de colores es exclusivamente rojo (en diversas tonalidades). Todos los motivos fueron ejecutados por medio de pintura lineal, tal vez aplicados con artefacto intermediario como crayones o trozos de pigmento rojo, color que se encuentra en forma natural en el reparo rocoso.

\section{Sector 3}

Presenta al menos dos motivos distinguibles, aportando el 4,6\% de la muestra total del sitio. Las medidas promediadas son $18,5 \times 17 \times 0,9 \mathrm{~cm}$, y la altura respecto del suelo es de $0,86 \mathrm{~m}$, aunque los motivos están dispuestos de forma altitudinalmente muy dispar, con uno a 1,73 $\mathrm{m}$ y el otro a $0,73 \mathrm{~m}$.

Ambos motivos están realizados por medio de la modalidad pintada de tipo lineal y en color rojo. La aplicación de la pintura parece haber sido de tipo digital en los dos casos. Los motivos son abstractos, lineales, uno de ellos curvilíneo (almenada), con buena preservación, aunque su contorno está remarcado por raspado, y otro rectilíneo (escaleriforme), de regular estado de conservación, identificado en forma previa por Schobinger (1956) como más de un motivo, posiblemente por estar separado por una diaclasa.

\section{Sector 4}

Se identificaron tres motivos, constituyendo un $7 \%$ de la muestra total del sitio. Las medidas promediadas son $22 \mathrm{x}$ $17,3 \times 0,86 \mathrm{~cm}$ y la altura respecto del nivel del suelo es 

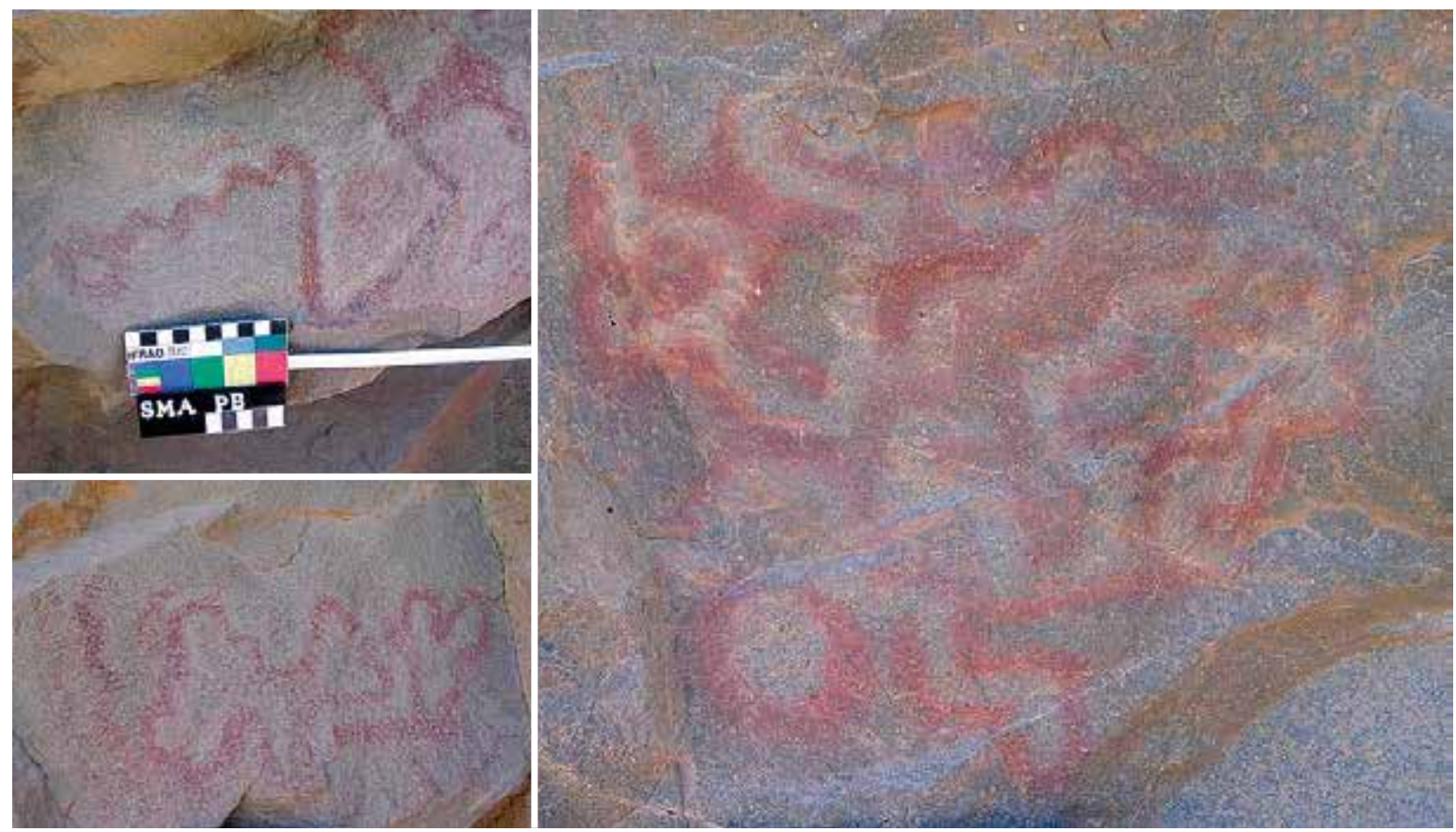

Figura 9. Motivos con pintura roja y negativo de pintura faltante, Sector 1.

Figure 9. Motifs with red paint and "negative" (missing) paint, Sector 1.

de 1,73 m. En relación con la mayor altura, la disposición de los motivos es en valores reales, ya que dos de los motivos están emplazados a 1,60 m y el tercero, a 2,0 m.

Todos los motivos son monocromos rojos, abstractos y lineales, dos de ellos rectilíneos (lineal, escaleriforme cerrado) y uno combinado (rectangular cerrado con líneas almenadas longitudinales en el interior). Los motivos se distinguen claramente, aunque han sido afectados por remarcado con tiza y vandalismo de tipo extractivo, con faltante de parte de soporte y motivo.

\section{Sector 5 (Soporte B)}

Se identificaron al menos dos motivos, constituyendo el $4,6 \%$ de la muestra total del sitio. Las medidas promediadas son 14 x 11 x $1,5 \mathrm{~cm}$ y la altura respecto del suelo es relativa, ya que, según imágenes de 1956, habría motivos emplazados a mayor altura sobre el mismo soporte, hoy día no visibles. De todos modos, de las dos muestras aquí descritas obtenemos un promedio de $0,52 \mathrm{~m}$, aunque sabemos que pueden llegar a un metro.

Ambos motivos monocromos rojos son abstractos, de disposición lineal y rectilínea en uno de los casos (lineal y cruciforme) y el otro pintado en cuerpo relleno y combinado (circular con apéndices triangulares unidos por su vértice al círculo). La conservación de los motivos en general es mala. Los registros de Schobinger de 1956 sobre este sector fueron posteriores a su visita de 1953 , obtenidos de una imagen fotográfica tomada por el Sr. Gonzalía, residente de San Martín de los Andes. Esto mostraría que las pinturas ya eran poco visibles en 1953. Pudimos detectar su presencia durante el crepúsculo, cuando hay suficiente luz natural, pero el sol no alumbra de frente el Soporte B. En la imagen presente en el trabajo del citado investigador se nota que las pinturas han sido remarcadas con color (tiza o crayón) para ser visibles y fotografiadas.

\section{Sector 6}

Se trata de al menos seis motivos, tres distribuidos sobre el techo-frente del sector reparado con suelo estratificado, y otros tres de ellos emplazados en el interior del reparo, en un segmento inferior de la pared en C XXVIII-C XXIX de planta del sitio, integrados como conjunto. La muestra de este sector constituye el 13,95\% de los motivos identificados en el sitio. Las medidas promediadas son $10,8 \times 8,3 \times 0,65 \mathrm{~cm}$, y la altura respecto del suelo promediada es de un metro. Esta última varía de acuerdo con la disposición de tres motivos aislados sobre el frente del techo del área reparada entre 1,18 m y 1,62 m de altura y el conjunto dispuesto en el interior, a 0,60 m del nivel actual del suelo, en un sector donde el techo del reparo es bajo y se accede agachado. 


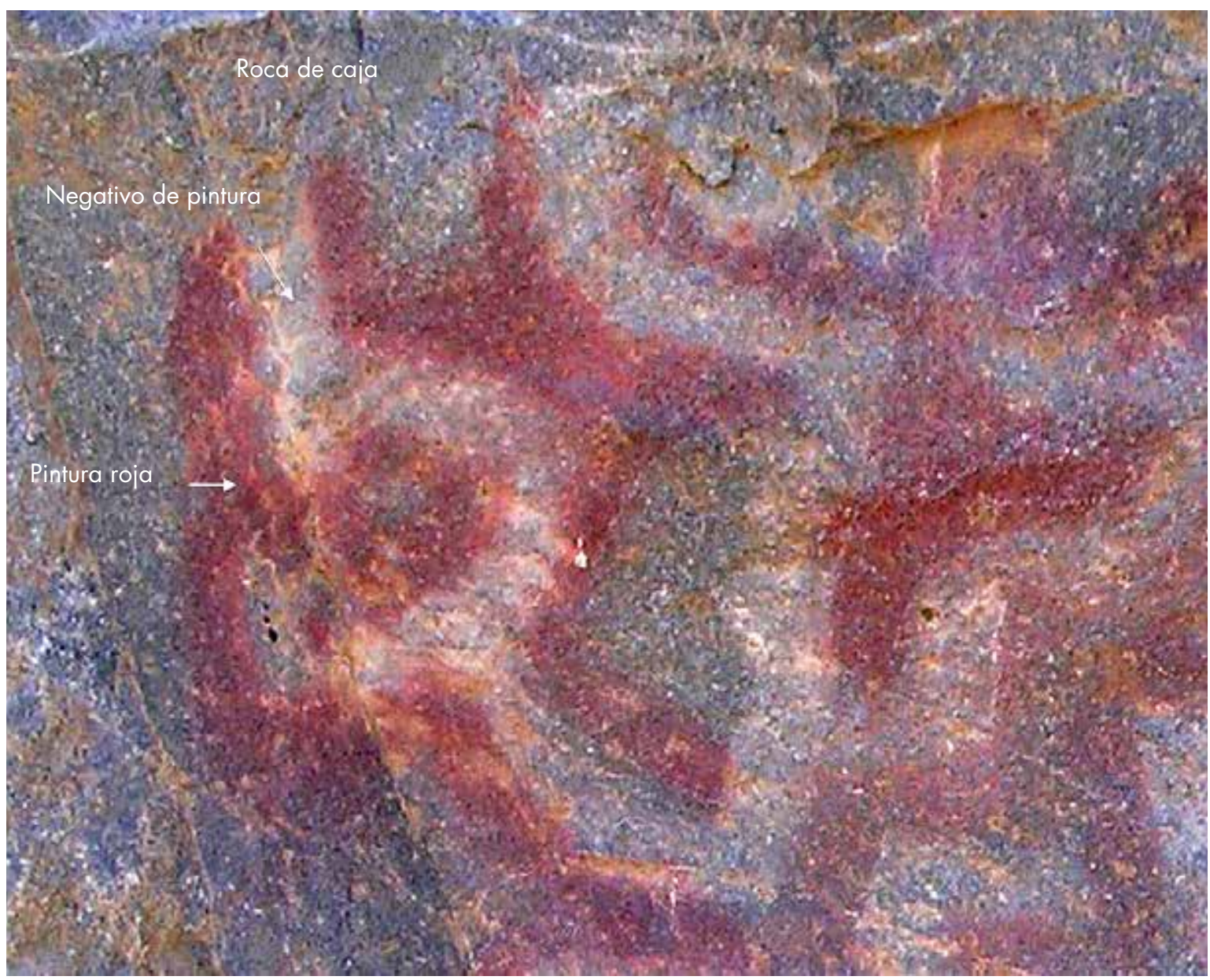

Figura 10. Detalle de motivo bicromo, Sector 1.

Figure 10. Detail of bicolor motif, Sector 1.

El total de los motivos fue realizado por medio de pintura monocroma roja. Al menos dos motivos pudieron ser distribuidos digitalmente, mientras otros cuatro pueden haber sido pintados con artefactos intermediarios. Todos los motivos son abstractos, de disposición lineal, tres de ellos rectilíneos (líneas, triángulos, cruciformes), curvilíneo (círculo) y dos combinados (círculos con líneas rectas radiales o sol, y líneas que presentan sectores rectos y curvos en forma de $\mathrm{H}$ ). Los motivos distribuidos aisladamente sobre el frente presentan buena conservación, mientras que el conjunto ubicado en el interior está deteriorado y remarcado con tiza.

\section{OTROS CONTEXTOS CERCANOS}

Existen otros tres sitios bajo reparo rocoso en cercanías de Paredón Bello, dos de ellos, Cueva Alihuén (Pérez et al. 2014) y Los Radales, aún inédito. El más conocido es Alero Gingin (Vignati 1935, 1963; Pérez et al. 2007). Otros sitios cercanos con pinturas rupestres se encuentran en el lago Lácar, en las zonas de Catritre y península de Quila Quina (Albornoz \& Cúneo 2000). Alguno de estos sitios incluyeron muestras tipo, junto con otros emplazados en el lago Nahuel Huapi, para postular una modalidad estilística singular, lacustre y boscosa, del "estilo de grecas" (sensu Menghin 1957), denominada "modalidad del ámbito lacustre boscoso del noroeste de la Patagonia" (Albornoz 1996, 2003; Albornoz \& Cúneo 2000), en adelante MALB. Esta se caracteriza por su emplazamiento sobre la primera línea de afloramientos rocosos sobre lagos, la pintura monocroma roja exclusiva o mayoritaria y figuras abstractas de trazo geométrico poco riguroso e importante proporción respecto de la muestra total de motivos representativos, especialmente antropomorfos esquemáticos con tridígitos en manos y pies (Albornoz 1996, 2003; Albornoz \& Cúneo 2000). Los motivos de Alero Gingin presentan similitudes a 
los descritos para esta modalidad, aunque agregan policromías y no se emplazan sobre la costa de un lago (Pérez et al. 2007). Los motivos de Paredón Bello son diferentes a esta modalidad estilística lacustre y boscosa caracterizada en sitios cercanos de lago Lácar, emparentada a los motivos de Alero Gingin en la vega Maipú. Sin embargo, más adelante analizaremos algunas características de ciertos motivos y técnicas compartidas entre esta modalidad estilística y la clásica caracterización de elementos del estilo de miniaturas y de grecas para retomar observaciones sobre algunas tendencias estilísticas propuestas a partir de asociaciones de motivos y técnicas entre estos estilos (Gradin 1999). En el caso de cueva Alihuén, emplazada en el margen norte de la vega Maipú, se caracteriza por la presencia de una acotada cantidad de motivos $(\mathrm{N}=14)$, predominantemente representativos esquematizados, incluyendo figuras biomorfas como camélidos y, en menor medida, motivos abstractos lineales, incluyendo rectilíneos y curvilíneos. En todos los casos se observan bicromías con rojo como color predominante, combinado con negro en el caso de los motivos representativos y negro o amarillo en el caso de los abstractos (Pérez et al. 2014).

El arte rupestre de Paredón Bello estaría asociado con los momentos más tardíos de la secuencia de arte rupestre de Patagonia, denominado "tendencia abstracta geométrica compleja” (sensu Gradin 1999), en adelante TAGC, propuesta a partir de la integración de algunos caracteres de los estilos de grecas y de miniaturas definidos por Menghin (1957). Cronológicamente, está asociada con momentos avanzados del Holoceno Tardío, cuyo inicio se ha estimado ca. 1300 años AP (Podestá et al. 2008; Hajduk et al. 2011), extendida en la vertiente oriental de los Andes, desde la zona cordillerana hasta la costa atlántica y casi los $-48^{\circ}$ de latitud como límite sur. Dentro de este modelo, la MALB, es una modalidad regional de la TAGC, de dispersión espacial más restringida al corredor de los lagos del bosque andinopatagónico que incluye los lagos Lácar, Nahuel Huapi, Gutiérrez, Mascardi y Guillermo y sitios de la cuenca del río Manso inferior y parte de los sitios de la Comarca Andina del Paralelo 42 (Albornoz \& Cúneo 2000; Bellelli et al. 2008; Podestá et al. 2008). Sin embargo, recientes trabajos sugieren que no se trata de una modalidad singular del corredor del sector oriental de los lagos de la cordillera de los Andes, ya que sus motivos presentan gran similitud con la decoración de la alfarería de la Tradición Bicroma Rojo sobre Blanco (Pérez et al. 2014) y, además, existen sitios como Villacura en el tramo de bosques de la cordillera andina occidental, específicamente en Los Ángeles, con presencia de antropomorfos dinámicos en escenas que remiten a las variaciones cromáticas y muchos otros caracteres compartidos con la denominada MALB, desde hace más de medio siglo (Montané 1966; Castelleti 2007).

La cronología de la TAGC se ha basado en el hallazgo estratigráfico de pigmentos que podrían haber servido para otros usos (pintura corporal, de cueros, ceremonial, etc.). Recordemos que la correspondencia entre signos rupestres y vestigios estratificados no es directa, más aun en sitios multicomponentes. Es posible, entonces, que las pinturas rupestres asignadas a esta tendencia estilística sean más recientes. Por ejemplo, existen referencias relativamente cercanas de sitios unicomponentes con arte rupestre de este estilo, como Rincón Chico 2/87 (Neuquén), donde dos fechados sitúan las ocupaciones hacia 700 AP (Crivelli Montero 2009: 61).

Podemos decir que Paredón Bello presenta características que lo diferencian estilísticamente de los sitios más cercanos emplazados en el mismo valle de Maipú y la margen sur del lago Lácar, presentando similitudes con registros de sitios emplazados sobre la cuenca media del río Neuquén (Gradin \& Pereda 1999; Cúneo 2010). Buena parte de estos se encuentran sobre las márgenes del arroyo Guayapa y el río Covunco (Cúneo 2010), donde al igual que Paredón Bello predomina la modalidad pintado y el color rojo, acompañado de rojo violáceo, ocasionalmente blanco fileteando el trazo de algunas figuras, y negro (Cúneo 2010). Los motivos presentes son también abstractos y representativos. Los primeros, adscribibles al estilo de grecas (Menghin 1957), compuestos de escaleriformes simples y complejos (ortogonales), laberintiformes escalonados, laberintiformes con grecas irregulares, puntos y puntiformes (ver Cúneo 2010). Entre los motivos representativos destacan los "oculados" con dos arcos y dos puntos a modo de cejas y ojos. En algunos casos, estos aparecen aislados y en otros, asociados o coronando figuras verticales en zigzag o segmentadas policromas, que según los autores corresponderían a representaciones antropomorfas, tal vez con ropajes o adornos especiales propios de personajes destacados dentro del grupo (Gradin \& Pereda 1999: 359; Cúneo 2010). La paleta de colores, predominantemente monocroma roja de los sitios, es 7,5 YR 4/8 (Munsell Soil Color Charts 1975), igual que los motivos de Paredón Bello, donde consignamos variaciones sutiles entre 7,5 YR 4/8 y 5/8 (Munsell Soil Color Charts 1975). Pigmento graso similar aflora naturalmente en el sitio. Otra característica compartida sería la presencia de motivos bicromos, incluyendo un color que también contorneó o fileteó a la representación base en rojo, pero en el caso de Paredón Bello no se conserva y deja su negativo en el soporte rocoso por meteorización natural (fig. 10). 
Aproximadamente $35 \mathrm{~km}$ de Paredón Bello en dirección noreste, a poco más de $5 \mathrm{~km}$ de la intersección de los ríos Chimehuín y Colloncura, hemos observado la presencia de pintura rupestre característica de la TAGC en paredones, aleros, abrigos y cuevas del inédito complejo arqueológico conocido localmente como "Los Chenques", en Estancia Huechahue, Junín de los Andes. Allí predominan conjuntos de motivos pintados monocromos y policromos característicos del estilo de grecas (Menghin 1957). Pero existen además aleros y paredones exclusivamente representados por pintura con motivos y técnicas características del estilo de miniatura (Menghin 1957). A diferencia de Paredón Bello, donde distintos motivos que integran la TAGC, están en un mismo soporte.

Las afinidades septentrionales de los motivos oculados están presentes —aunque escasamente- en sitios del "estilo de Guaiquivilo" (Niemeyer \& Weisner 1972-1973: 431; Fernández 2001: 375) y de paralelas, en las lagunas de Epu Laufquén. También aparecen en la quebrada de la Piedra Pintada, localizados en el departamento de Añelo, a $35 \mathrm{~km}$ al este de la margen izquierda del río Neuquén y fuera de su cuenca (Fernández 1978: 64-65). En las ocupaciones alfareras tempranas de Chenque Haichol hay un objeto de madera descrito como "vinculable" con los motivos oculados (Cúneo 2010: 246, fig. 18). Mientras que en la región colindante occidental cordillerana, las representaciones vinculables a estos motivos oculados son abundantes durante el Período Alfarero Temprano y están presentes en una gran diversidad de soportes y/o materias primas más o menos portables, como, por ejemplo, entre los motivos de búhos del "estilo de La Araucanía" en el arte rupestre; la alfarería antropomorfa modelada y los apéndices agregados por pastillaje en pipas, máscaras (kollón) y esculturas de piedra, varias ubicadas en la cercana región de Pucón; en tiempos históricos, en los rewes y los kollón de madera e incluso en la platería (figs. 11a y b, 12 y 13).

Al igual que en la vega Maipú, las pinturas de la cuenca media del río Neuquén están emplazadas en paredones rocosos, aleros y cuevas. Pero en el caso de estas últimas, asociadas con sitios que habrían tenido diferentes funcionalidades, como lugares de actividades múltiples, incluyendo campamentos residenciales.

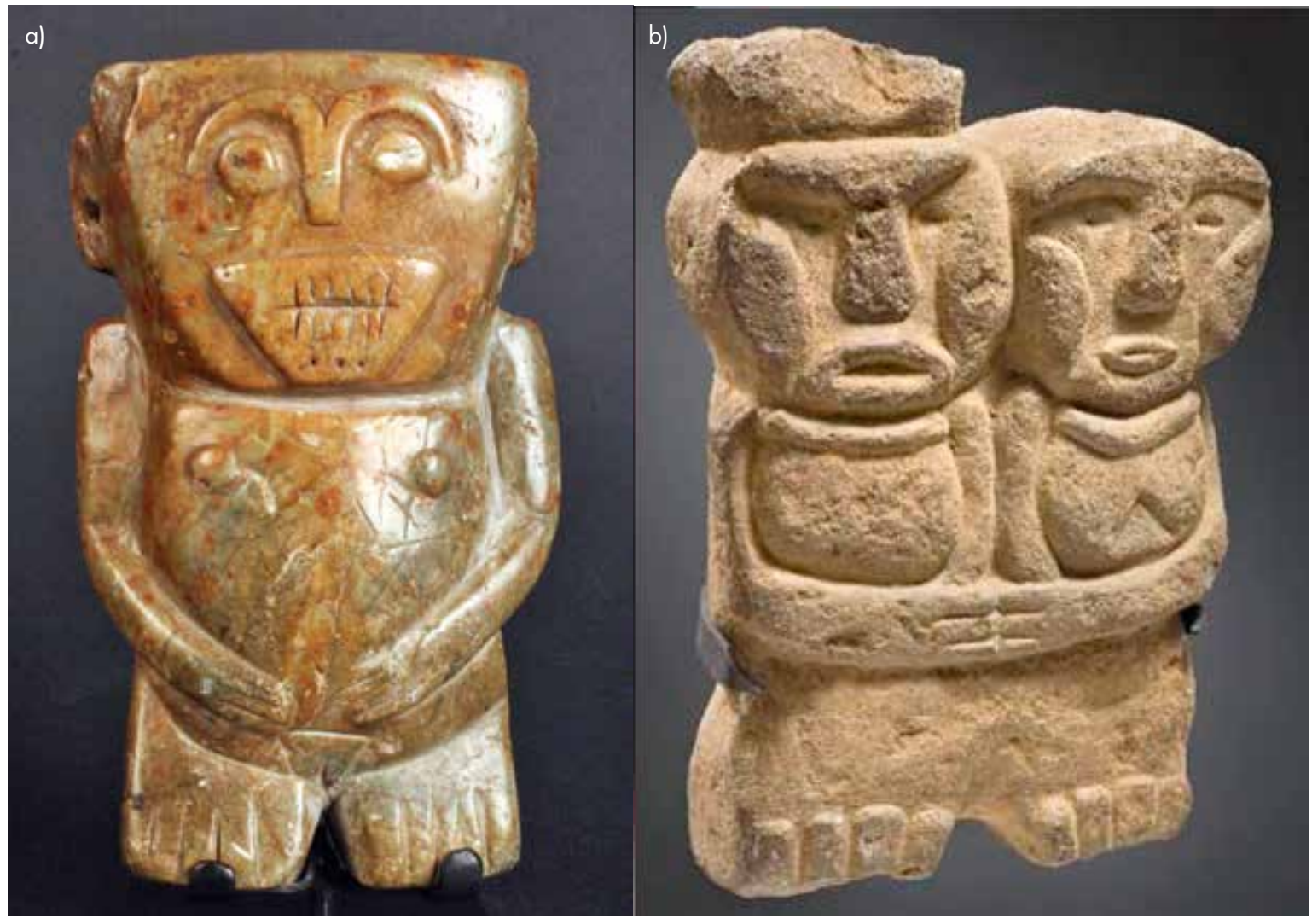

Figura 11. a) Pipa antropomorfa de piedra de ca. 1250 DC (Ferreccio Podestá 1991 [1931]: 48, fig. 41), Museo Chileno de Arte Precolombino $\mathrm{N}^{\circ} 216$; b) Escultura del mismo período, típica de la región centro sur de Chile.

Figure 11. a) Anthropomorphic stone pipe ca. AD 1250 (Ferreccio Podestá 1991 [1931]: 48, fig. 41), Museo Chileno de Arte Precolombino $N^{\circ} 216$; b) Sculpture from the same period, typical of south-central Chile. 
En cambio, las pinturas de Paredón Bello y otros emplazamientos con pinturas rupestres de la vega Maipú están ubicados en sectores más asociados con divisaderos o campamentos de actividades específicas. Los asentamientos residenciales y de usos múltiples es probable que estén ubicados en inmediata cercanía, como es el caso de la localidad arqueológica Meliquina, a unos $20 \mathrm{~km}$ de distancia sobre vertiente opuesta del mismo cordón de Chapelco, donde los reparos rocosos con pinturas rupestres están asociados con sitios de actividad restringida, funcionalmente articulados con grandes campamentos de actividades múltiples a cielo abierto (Pérez 2010a).

El segmento reparado y con sedimentación de Paredón Bello, identificado como Sector 6, presenta excavaciones furtivas en cuyos sedimentos removidos se observan algunos tiestos monocromos pardos muy quemados, y en los perfiles evidencias de fogones a partir de carbones y ceniza. Lamentablemente, además de la remoción, debemos agregar que el sitio fue refugio de pastoreo de ovejas por más de un siglo, así que el escaso sedimento presente se encuentra también cubierto de coprolitos y saturado de la orina de ovicaprinos. Por lo tanto, el grado de contaminación evidente de la muestra impide realizar dataciones convencionales.

$\mathrm{Al}$ menos dos motivos que se emplazan en planos de rocas muy poco visibles en el Sector 1 , remiten dentro del esquema clásico al "estilo de miniaturas" (Menghin 1957), asociado cronológicamente a períodos alfareros, ofreciéndonos la posibilidad de discutir —bajo un nuevo contexto regional - la caracterización de la presencia de pinturas asignables a la TAGC a partir de los elementos regionales presentes y seleccionados de los estilos previamente descritos por Menghin (1957). Por ejemplo, los motivos y las técnicas que sirvieron para caracterizar un "estilo de miniaturas", entre los

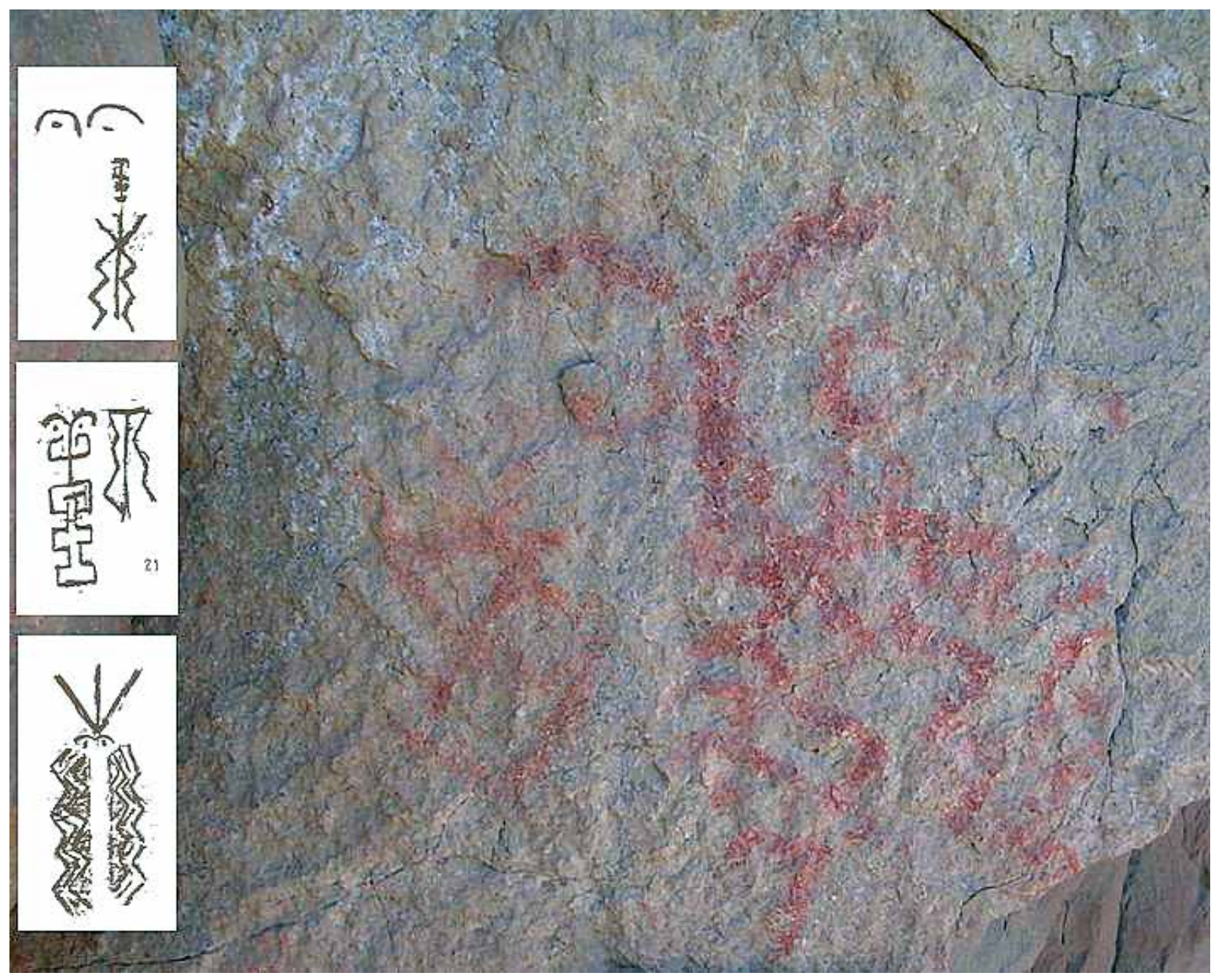

Figura 12. Motivo oculado de Paredón Bello y registros similares de sitios de la cuenca media del río Negro sobre sector izquierdo, tomado de Gradin y Pereda (1999: 364, fig. 16, y 365, figs. 20 y 21).

Figure 12. Motif with eyes at Paredón Bello. On the left: similar motifs from sites in the middle Río Negro basin as recorded by Gradin $\mathcal{E}$ Pereda (1999: 364, fig. 16, and 365, figs. 20 and 21). 


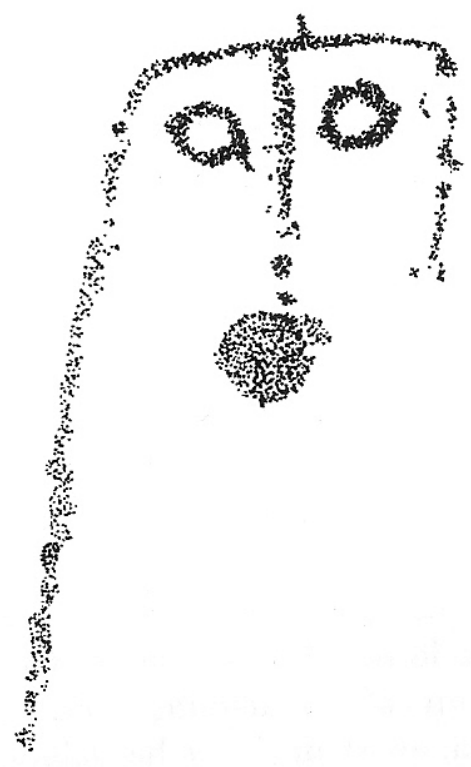

Figura 13. Motivo oculado del "estilo de paralelas" (Fernández 2000: 81 , fig. 11 , motivo II).

Figure 13. Motif with eyes in the "parallel style" (Fernández 2000: 81, fig. 11, motif II).

que destaca la delicadeza del diseño y su ejecución por medio de una pluma; el color rojo predominante (aunque hay otros colores) y motivos consistentes en líneas finamente onduladas o escalonadas, preferentemente conformando combinaciones triangulares, a veces en recuadros; líneas almenadas, diminutas figuras en forma de $Z$ y series de finísimos triángulos rojos (Menghin 1957: 76, fig. 21). Tanto producto de nuestras investigaciones en San Martín de los Andes, como por medio de la comparación con el registro de sitios de otras áreas, como la Comarca Andina del Paralelo $42^{\circ}$, observamos la presencia y recurrencia de motivos escalonados semicirculares de trazo fino, motivos triangulares alineados y otras figuras geométricas pertenecientes a la TAGC, junto a motivos singulares de la MALB (ver Podestá et al. 2008: 149, figs. 4 y 5). Los motivos representativos esquematizados biomorfos, específicamente antropomorfos con tres dedos en sus extremidades característicos del MALB, son conocidos en la región centro-sur de Chile como "hombres rana", representaciones del Ngen'ko, N'gen o figura protectora del agua, que suele encarnar a la deidad máxima Ngenechen (Mera \& Lobos 2008; Pérez 2010b). En la alfarería de San Martín de los Andes, al igual que en el resto de la cuenca hidrográfica valdiviana, las representaciones anfibiomorfas son recurrentes a partir de la aplicación de protúberos (sensu Mera \& Lobos 2008; Pérez 2010b) a modo de ojos, modelados o agregados
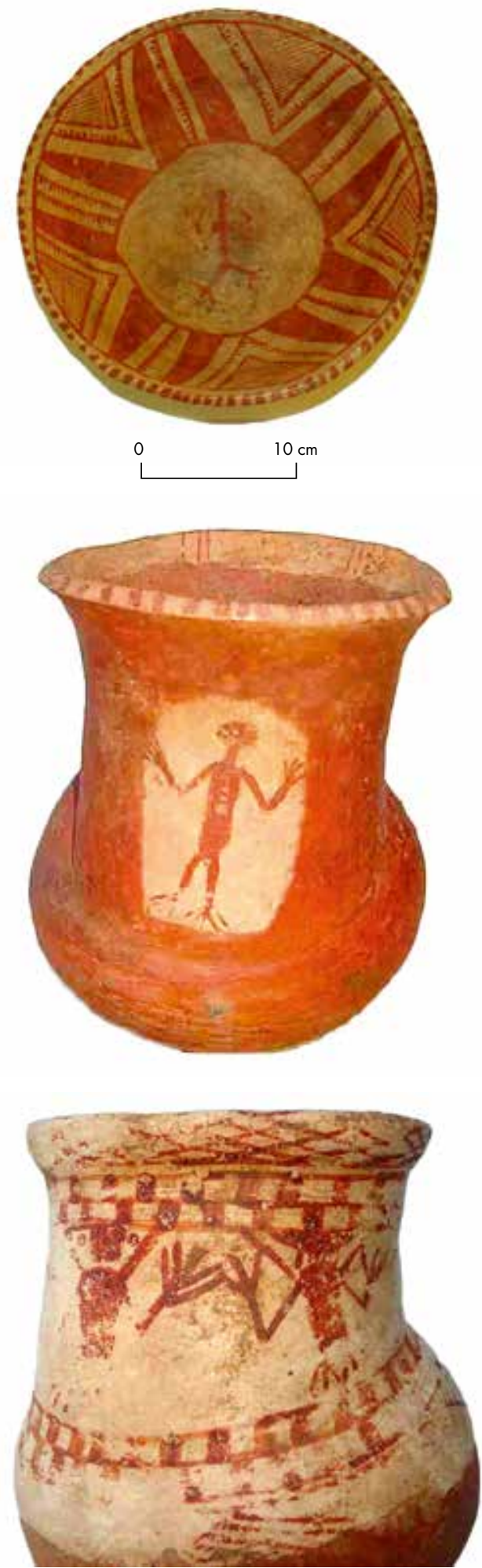

Figura 14. Vasijas con pintura geométrica roja y motivos zooantropomorfos (Bahamondes Muñoz 2009: 140, fig. b, y 142, figs. b-d). Figure 14. Ceramic vessels with red geometric paint and zooanthropomorphic figures (Bahamondes Muñoz 2009: 140, fig. b, and 142, figs. $b-d$ ). 
como apéndices en el sector superior de la asa desde el Período Alfarero Temprano del centro-sur de Chile, conocido como Complejo Pitrén, mientras que los motivos zooantropomorfos pintados (metamorfosis del hombre y rana) están presentes en el Período Alfarero Tardío (Aldunate 1989; Dillehay 1990) o Tradición Bicroma Rojo sobre Blanco (Adán \& Alvarado 1999; Bahamondes Muñoz 2009; Adán \& Mera 2011; Pérez 2011) en vasijas encontradas en Concepción, Cañete y Angol (ver Bahamondes Muñoz 2009) (fig. 14).

En suma, Menghin señalaba en la década de 1950 motivos recurrentes en la alfarería pintada de tipo Inca, e incluso diaguita-chileno de cronología posiblemente preincaica en representaciones rupestres (Menghin 1957:76). Estas similitudes registradas entre motivos y técnica de ejecución del estilo de miniaturas con alfarería pintaba es sustancialmente interesante, ya que si bien en su contexto original esta comparación era un carácter difusionista de la escuela históricocultural, hoy día cobra valor como hipótesis bajo otros paradigmas y especialmente a partir de la posterior descripción durante la década de 1960 de complejos alfareros que incluyeron la pintura geométrica con varios atributos compartidos con elementos que definen la MALB. Hemos reconocido ciertos caracteres en el arte rupestre de sitios de la vega de Maipú y lago Lacar, pertenecientes a la cuenca hidrográfica valdiviana y la alfarería pintada típica del Período Alfarero Tardío desde el siglo xI, en los estilos cerámicos El VergelValdivia o Tradición Bicroma Rojo sobre Blanco de amplia distribución en el sector occidental de la cuenca (Adán \& Alvarado 1999; Reyes Álvarez 2009; Adán \& Mera 2011) y cada vez más recurrente en la vertiente oriental (Pérez 2011) (fig. 15).

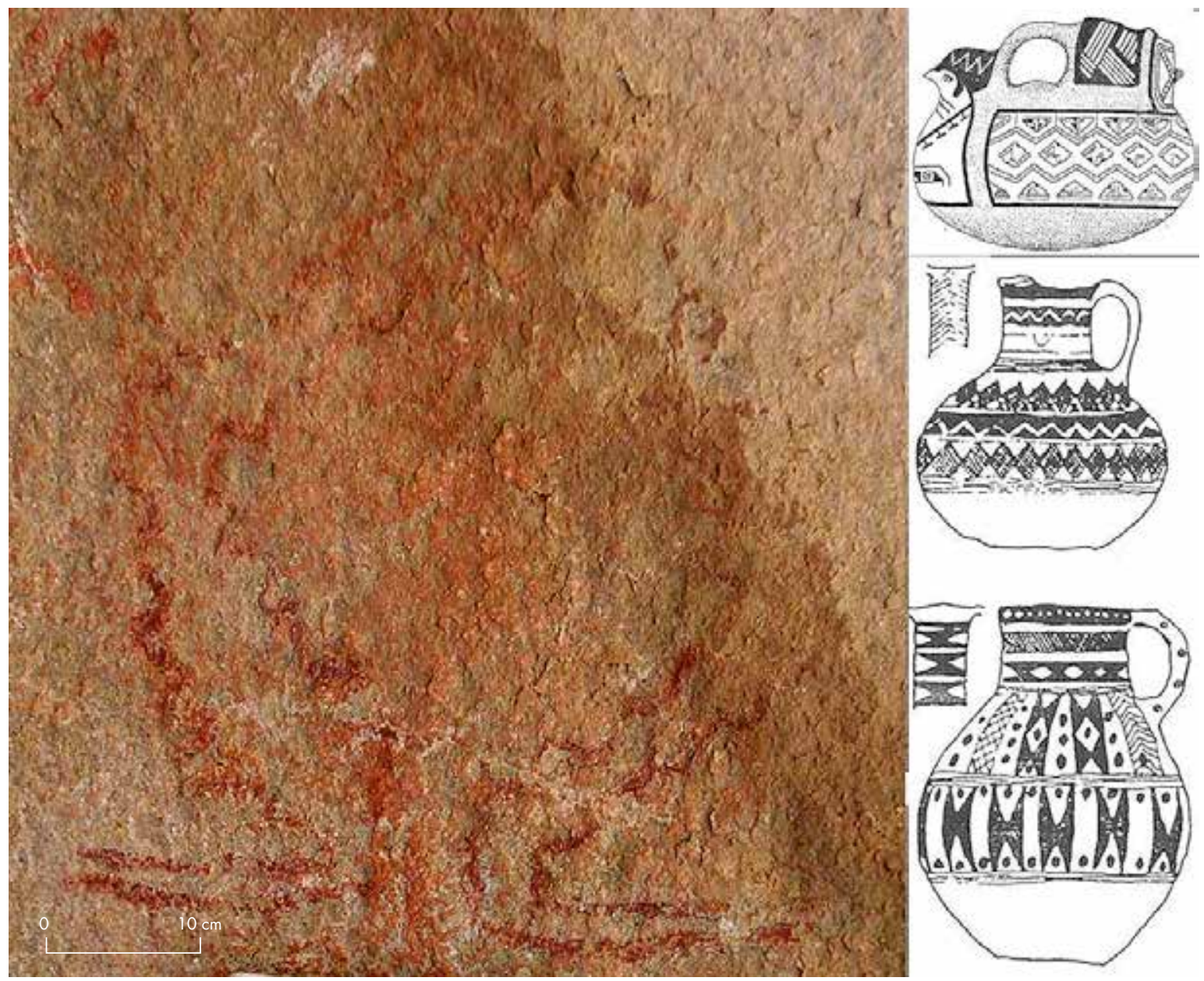

Figura 15. Izquierda: motivos ejecutados con pincel o pluma de Paredón Bello. Derecha: Sector superior, vasija diaguita tomada de Menghin (1957: 77, fig. 22), como ejemplo de miniaturas; sector inferior, vasijas El Vergel-Valdivia del centro-sur de Chile y Neuquén. Figure 15. Left: motifs at Paredón Bello made with a brush or feather. Upper right: Diagram of a Diaguita vessel as recorded by Menghin (1957: 77, fig. 22) as an example in miniature. Lower right: Sketches of El Vergel-Valdivia vessels from south-central Chile and Neuquén. 


\section{CONSIDERACIONES FINALES}

Las pinturas rupestres de Paredón Bello pueden ser asignadas a la TAGC, pero presentando ciertos elementos o motivos novedosos en el contexto arqueológico de la cuenca del valle de Lácar y del Valdivia en general, e incluso con el "estilo de La Araucanía". La similitud de las representaciones, colores y técnicas de ejecución con sitios conocidos de la cuenca media del río Neuquén, Departamento Picunches, en un ambiente de ecotono Bosque Andino-Estepa, con desarrollo de Araucaria araucana permiten postular una afinidad cordillerana o noroccidental, con asociación a partir de los motivos oculados con modalidades comunes a ambas vertientes de la cordillera (Guaquivilo y Paralelas) (Fernández 2000; Hajduk \& Cúneo 2009; Cúneo 2010). Hasta la fecha, no sabemos de otros caracteres que remitan a la margen norte del río Neuquén como alfarería gris incisa con bases formatizadas, y las puntas triangulares apedunculadas siguen siendo escasas (Schobinger 1957; Bórmida 1964; Prates 2008). Tampoco hemos encontrado en sitios del cordón de Chapelco materias primas como obsidianas procedentes de las fuentes de Portada Covunco y Cerro Huenul (Pérez et al. 2012). Por otra parte, postulamos necesario analizar más en detalle vinculaciones entre contextos trasandinos y la TAGC y su supuesta modalidad regional MALB. Especialmente los motivos abstractos pintados con crayón, pluma o pincel de trazo fino, entre 0,1 y $0,2 \mathrm{~cm}$ de ancho, asociados en algunos sitios a antropomorfos dinámicos con tridígitos comúnmente denominados en Chile "anfibiomorfos", cuya variedad cromática además habíamos previamente vinculado a algunas vasijas pintadas del Período Alfarero Tardío del centro-sur de Chile, denominado Tradición Bicroma Rojo sobre Blanco (Pérez 2011; Pérez et al. 2014). Al mismo tiempo, el motivo oculado de Paredón Bello fue realizado combinando pintura y relieve. Este último nos remite a las representaciones escultóricas antropomorfas presentes desde momentos finales del Período Alfarero Temprano del área centro-sur de Chile.

En suma, más allá del carácter integrador de motivos en una TAGC, las pinturas de Paredón Bello constituyen hasta el momento la más importante característica compartida con contextos emplazados hacia el norte de la cuenca del río Neuquén, a la vez que nos permite retomar antiguas discusiones y plantear nuevas hipótesis sobre el arte rupestre norpatagónico, su vinculación con otros soportes durante tiempos alfareros y la circulación de información y personas entre ambas vertientes de la cordillera de los Andes.

RECONOCIMIENTOS Luis Hermman, Pablo Arias y Marina Smith colaboraron en los trabajos de campo para el relevamiento del sitio. Los evaluadores anónimos realizaron comentarios y sugerencias muy acertadas y constructivas para mejorar sustancialmente esta contribución. Los autores somos únicos responsables de los comentarios expuestos.

\section{REFERENCIAS}

Adán, L. \& M. Alvarado, 1999. "Análisis de colecciones alfareras pertenecientes al complejo Pitrén: Una aproximación desde la arqueología y la estética. En Soplando en el viento... Actas de las III Jornadas de Arqueología de la Patagonia, pp. 245268. Neuquén-Buenos Aires: INAPL y Universidad Nacional del Comahue.

ADÁN, L. \& R. MERA, 2011.Variabilidad interna en el Alfarero Temprano del Centro-Sur de Chile. El Complejo Pitrén en el valle Central del Cautín y el Sector Lacustre Andino. Chungara 43 (1): 3-23.

Albornoz, A., 1996. Sitios con arte rupestre en los alrededores del lago Nahuel Huapi (río Negro). En Arqueología. Solo Patagonia, J. Gómez Otero, Ed., pp. 123-130. Puerto Madryn: CENPAT-CONICET.

- 2003. Estudios recientes del arte rupestre en la Provincia de Río Negro (desde fines de 1970 a la actualidad). En Arqueología de Río Negro, C. J. Gradin, A. M. Aguerre \& A. M. Albornoz, Comps., pp. 79-94. Río Negro: Secretaría de Estado de Río Negro.

Albornoz, A. M. \& E. M. CúneO, 2000. Análisis comparativo de sitios con pictografías en ambientes lacustres boscosos de Patagonia septentrional: Lagos Lácar y Nahuel Huapi (provincias del Neuquén y del [sic] Río Negro, República Argentina). En Arte en las rocas. Arte rupestre, menhires y piedras de colores en Argentina, M. M. Podestá \& M. de Hoyos, Eds., pp. 163-174. Buenos Aires: Sociedad Argentina de Antropología/INAPL.

AldunAte, C., 1989. Estadio Alfarero en el Sur de Chile. En Culturas de Chile. Prebistoria desde sus orígenes hasta los albores de la conquista, J. Hidalgo, V. Schiappacasse, H. Niemeyer, C. Aldunate \& I. Solimano (Eds.), pp. 329-348. Santiago: Editorial Andrés Bello.

Bahamondes Muñoz, F., 2009. La cerámica prehispánica tardía de Araucanía Septentrional: el complejo arqueológico El Vergel y su relación con la hipótesis del proceso de andinización. Memoria para optar al título de profesional en Arqueología. Universidad de Chile, Facultad de Ciencias Sociales, Departamento de Antropología, Santiago.

Bellelli, C.; V. Scheinsohn \& M. M. Podestá, 2008. Arqueología de pasos cordilleranos: Un caso de estudio en Patagonia Norte durante el Holoceno Tardío. Boletín del Museo Chileno de Arte Precolombino 13 (2): 37-55.

Bórmida, M., 1964. Arqueología de la costa norpatagónica. Trabajos de Prebistoria 16: 7-108, Buenos Aires.

Castelleti, J., 2007. El arte rupestre de la zona boscosa y lacustre cordillerana del sur de Chile y sus relaciones con regiones vecinas. Boletín de la Sociedad Chilena de Arqueología 40: 57-71.

Cúneo, M. E., 2010. Arqueología de la cuenca del río Neuquén. En Los ríos mesetarios norpatagónicos. Aguas generosas del Ande al Atlántico, R. F. Masera, Coord., pp. 197-259. Río Negro: Ministerio de Producción de Río Negro.

Crivelli Montero, E. A., 2009. Estratigrafía y cronología de Rincón Chico 2/87. En Arqueología de rescate en Rincón Chico, provincia del Neuquén, E. A. Crivelli Montero, M. M. Fernández \& M. S. Ramos, Eds., pp. 55-62. Buenos Aires: Editorial Dunken.

Dillehay, T. D., 1990. Araucanía: Presente y Pasado. Santiago: Editorial Andrés Bello.

FERnÁndez, J., 1978. Corpus de arte prehistórico neuquino (Primera Parte). Revista del Museo Provincial 1: 17-93, Neuquén.

— 2000. Las piedras pintadas con marcas de la cordillera del Viento. Arte rupestre en el departamento Minas, Neuquén, Argentina. Buenos Aires: Publicaciones de la SAA.

_ 2001. Personajes oculados en el arte rupestre neuquino: Entre lo antropomorfo y lo ornitomorfo. En Libro de resúmenes del XIV 
Congreso Nacional de Arqueología Argentina, p. 375. Rosario: Universidad Nacional de Rosario, Facultad de Humanidades y Artes.

FERRECCIO PODESTÁ, M., 1991. El epistolario cronístico valdiviano y el scriptorium de conquista [1931]. Barcelona: Editorial Lumen.

Fidalgo, F. \& N. PORro, 1978. Geología glacial. Geología y recursos naturales del Neuquén. VII Congreso Geológico Argentino: 129-136. Neuquén.

Flint, R. F. \& F. Fidalgo, 1964. Glacial geology of the flank of the Argentine Andes between $39^{\circ} 10^{\prime}$ lat. S and $41^{\circ} 20^{\prime}$ lat. S Geological Society American Bulletin 75 (4): 335-352.

Funes, M.C.; J. Sanguinetti, P. Laclau, L. Maresca, L. García, F. Mazzieri, L. Chazarreta, D. Bocos, F. D. Lavalle, P. Espósito, A. Gonzáles \& A. Gallardo, 2006. Diagnóstico del estado de conservación de la biodiversidad en el Parque Nacional Lanín: Su viabilidad de protección en el largo plazo. Informe final. Parque Nacional Lanín, San Martín de los Andes, Neuquén.

Gollán, J., 1958. Zoogeografía. La Argentina. Suma de geografía III: 209-359. Buenos Aires: Peuser.

Gradin, C. J., 1978. Algunos aspectos del análisis de las manifestaciones rupestres. Revista del Museo Provincial 1. Arqueología, Neuquén.

_ 1988. Caracterización de las tendencias estilísticas del arte rupestre de la Patagonia (provincias de Río Negro, Chubut y Santa Cruz, República Argentina). En Contribución al estudio del arte rupestre argentino $N^{\circ} 2$. Nuevos estudios de arte rupestre argentino, C. J. Gradin \& J. Schobinger, Eds., pp. 54-67. La Paz: SIARB.

— 1999. Sobre las tendencias del arte rupestre de Patagonia argentina. En Segundas Jornadas de Investigadores en Arqueología y Etnohistoria del Centro-Oeste del País, pp. 85-99. Río Cuarto: Universidad de Río Cuarto.

Gradin, C. \& I. Pereda, 1999. Arte rupestre del área de investigaciones Llamuco, provincia del Neuquén: primer informe. En Soplando en el viento... Actas de las III Jornadas de Arqueología de la Patagonia, pp. 357-370. Neuquén-Buenos Aires: INAPLUniversidad Nacional del Comahue.

HajDuK, A. \& M. E. CúNEO. 2009. Representaciones rupestres en la cuenca del río Curi Leuvú (departamento Chos Malal, Provincia del Neuquén, República Argentina). Informe preliminar. En Arqueología de la Patagonia. Una mirada desde el último confin, Tomo 1, M. Salemme, F. Santiago, M. Álvarez, E. Piana, M. Vázquez \& M. E. Mansur, Comps., pp. 515-526. Ushuaia: Editorial Utopías.

HajDuK, A.; A. M. Albornoz \& M. J. LeZCANo, 2011. Espacio, cultura y tiempo: El corredor bioceánico norpatagónico desde la perspectiva arqueológica. En Cultura y espacio. Araucanía-Norpatagonia, P. Navarro Floria \& W. Delrío, Comps., pp. 262-292. Río Negro, IIDyPCa-Universidad Nacional de Río Negro.

Menghin. O. F. A., 1957. Estilos de arte rupestre de Patagonia. Acta Praehistórica III/IV: 49-120. Buenos Aires.

Mera, C. R. \& G. A. Lobos, 2008. Anfibios y reptiles en el imaginario cultural de Chile. En Herpetología de Chile, Capítulo II, M. A. Vidal \& A. Labra, Eds., pp. 55-76. Santiago de Chile: Science Verlag.

Montané, J., 1966. Pictografías y petroglifo de Villucura (Prov. de Biobío, Chile). Leído en la sesión No 316 de la Academia Chilena de Ciencias Naturales, pp. 377-381.

Mostny, G. \& H. Niemeyer, 1983. Arte rupestre chileno. Santiago: Ministerio de Educación, Departamento de Extensión Cultural

Munsell SOIL Color CharTs, 1975. Munsell Book of Color. Macbeth Division of Kollmorgen Instruments Corporation, Baltimore.

Niemeyer, H. \& L. WeISNer, 1972-1973. Los petroglifos de la cordillera andina de Linares (Provincias de Talca y Linares, Chile). En Actas del vi Congreso Nacional de Arqueología Chilena. Boletín de Prehistoria, Número especial: 405-470, Santiago de Chile.
Pérez, A. E., 2010a. La localidad arqueológica "Lago Meliquina", Dto. Lácar, Neuquén. El registro arqueológico del interior y borde de bosque en Norpatagonia. En Actas y Memorias del XVII Congreso Nacional de Arqueología Chilena [2006]: 1515-1528, Valdivia.

— 2010b. La mirada de Ngenechen: Representaciones anfibiomorfas aplicadas al pastillaje en la alfarería de la Patagonia Noroccidental Argentina. Comechingonia 13: 9-20. Córdoba: UNRC.

-2011. Algunas reflexiones sobre la alfarería del Centro-Sur de Chile y ambientes lacustres precordilleranos de la Patagonia septentrional argentina. En Cultura y espacio. Araucanía-Norpatagonia, P. Navarro Floria \& W. Delrío, Comps., pp. 293-311. Río Negro: IIDyPCa-Universidad Nacional de Río Negro.

Pérez, A.; F. GonZÁlez \& M. Smith, 2007. Sobre la "pecaminosa lámina y la malhadada pictografía de Gingin". San Martín de los Andes, Neuquén. En Patrimonio cultural: La gestión, el arte, la arqueología y las ciencias exactas aplicadas, C. Vázquez \& O. Palacios, Eds., pp. 269-279. Buenos Aires: CONEA.

Pérez, A. E.; L. G. López \& C. R. STERn, 2012. Descripción y caracterización química de distintas fuentes y tipos de obsidiana en la cordillera de los Andes, sudoeste del Neuquén, Norpatagonia argentina. En Actas y Memorias del XVII Congreso Nacional de Arqueología Chile [2009], pp. 459-469, Valparaíso.

Pérez, A. E.; C. Diez Fernández-Lomana \& R. A. Alcalde, 2014. La Cueva Alihuén. Nuevos registros de pinturas rupestres en la vega de Maipú (San Martín de los Andes, Patagonia). Arqueología Iberoamericana 22: 19-36, Cádiz.

Podestá, M.; C. Bellelli, R. labarca, A. M. Albornoz, A. B. Basini \& E. Tropea, 2008. Arte rupestre en pasos cordilleranos del Bosque Andino Patagónico (El Manso, Región de Los Lagos y Provincia de Río Negro, Chile-Argentina). Magallania 36 (2): 143-153, Punta Arenas.

Prates, L., 2008. Los indigenas del río Negro. Un enfoque arqueológico. Buenos Aires: Sociedad Argentina de Arqueología.

Rabassa, J.; E. Everson, G. Schlieder, J. M. Clinch, G. Stephens \& P. ZiLTER, 1987. Edad Pre-Pleistoceno superior de la glaciación El Cóndor, valle del río Malleo, Neuquén. República Argentina. En Actas del x Congreso Geológico Argentino, Tomo 3, pp. 261263, San Miguel de Tucumán.

ReYES Álvarez, V., 2009. Microvariaciones en las cadenas operativas de producción de cerámica durante el Período Alfarero Tardío del área lacustre de los andes occidentales, lat. $39^{\circ}$ sur, Patagonia septentrional. En Arqueología de Patagonia. Una mirada desde el último confin, Tomo 2, M. Salemme, F. Santiago, M. Álvarez, E. Piana, M. Vázquez \& E. Mansur, Comps., pp. 1159-1176. Ushuaia: Editorial Utopías.

RoDríguez, S. N., 1999. Nociones generales sobre la prehistoria del suroeste de Neuquén. En El libro de los 100 años. Libro del centenario de San Martín de los Andes, pp. 39-55. Comisión del Centenario, Eds. Bahía Blanca: Austral Visión.

SCHOBinger, J. C., 1956. El arte rupestre de la Provincia del Neuquén. Anales de Arqueología y Etnología XII: 112-227. Mendoza: Universidad Nacional de Cuyo.

— 1958. Arqueología de la Provincia del Neuquén. Estudio de los hallazgos moviliares. Anales de Arqueología y Etnología XIII: 6-232. Mendoza: Universidad Nacional de Cuyo.

Schroo, S.; R. Sbrancia \& F. Pereira, 2006 Ms. Ampliación del informe de factibilidad ambiental. Barrio Alihuén, Fracción "A", Chacra 9.

Vignati, M. A., 1935. Una pictografía de los alrededores de San Martín de los Andes. Revista Geográfica Americana IV: 407410, Buenos Aires.

— 1963 Rectificaciones respecto a una pretendida pictografía indígena de San Martín de los Andes. En Primer Congreso del Área Araucana Argentina, Tomo 2, pp. 189-191. Buenos Aires: Peuser. 
